\title{
Pengaruh Disiplin Kerja Terhadap Kinerja Pekerja Pt.Semen Bosowa Di Banyuwangi
}

\author{
Githa Dwi Putri $^{* 1}$, Endang Dwiyanti ${ }^{1}$, Ayik Mirayanti Mandagi ${ }^{2}$ \\ ${ }^{1}$ Departement of Occupational Safety and Health, Faculty of Public Health, \\ Banyuwangi Campus, Airlangga University, indonesia \\ ${ }^{2}$ Departement of Epidemiology, Faculty of Public Health, Banyuwangi Campus, \\ Airlangga University, Indonesia
}

Author's Email Correspondence (*): githa.dwi.putri-2016@fkm.unair.ac.id Phone : +6282131465118

\begin{abstract}
ABSTRAK
Sumber daya manusia atau pekerja merupakan asset bagi sebuah perusahaan, dimana pekerja ini lah yang dapat memberikan perusahaan nilai. Pekerja ini juga yang nanti nya dituntut untuk mempunyai moral perilaku kerja, salah satu moral tersebut adalah Disiplin Kerja. Terbukti bahwasanya jika disiplin kerja dalam suatu perusahaan buruk maka hasil dan proses produksi suatu perusahaan akan terhambat, sehingga kinerja pekerja pun akan ikut menurun. Setelah dilakukan pengambilan data awal di PT. Semen Bosowa Banyuwangi ditemukan bahwa terdapat $72 \%$ pekerja yang memliki disiplin kerja masih dibawah total rata - rata score $(4,02)$, dan masih terdapat $27 \%$ pekerja yang masih memiliki Kinerja dibawah total rata - rata score $(3,88)$. Hal ini membuat peneliti tertarik untuk melihat pengaruh antara Disiplin Kerja terhadap Kinerja Pekerja di PT. Semen Bosowa Banyuwangi. Penelitian ini merupakan penelitian analitik observasional dengan pendekatan kuantitatif dan rancang bangun cross-sectional study. Sampel penelitian sebesar 73 orang, diambil secara acak menggunakan disproportionate stratified random sampling. Pengumpulan data meliputi Disiplin Kerjan dan Kinerja Pekerja. Analisis data yang digunakan dalam penelitian ini adalah uji regresi linear sederhana. Hasil penelitian didapatkan bahwa terdapat pengaruh antara Disiplin Kerja terhadap kinerja pekerja $(\Sigma=0.001)$. Kesimpulan dari penelitian ini adalah meskipun Disiplin Kerja yang dimiliki Pekerja di PT. Semen Bosowa Banyuwangi tinggi namun Kinerja pekerja yang berada di PT. Semen Bosowa Banyuwangi sudah baik tetapi belum optimal.
\end{abstract}

Kata Kunci: Disiplin Kerja, Kinerja

Published by:

Tadulako University

Address:

Jl.Soekarno Hatta KM 9. Kota Palu, Sulawesi Tengah, Indonesia.

Phone: +628114120202

Email: Preventif.fkmuntad@gmail.com
Article history

Received :09 112020

Received in revised form : 10112020

Accepted : 22112020

Available online : 30062021 


\begin{abstract}
Human resources or workers are assets for a company, where these workers can give the company value. These workers are also required to have moral behavior, one of these morals is the Discipline of Work. It is proven that if the work discipline in a company is bad, the results and production processes of a company will be hampered, so that the worker's performance will also decreasing. Preliminary research were done in PT. Semen Bosowa Banyuwangi, and the results are there is still 72\% workers that have Work discipline below the total average score (4,02), and there are still $27 \%$ workers that have Work Performance below the total average $(3,88)$. This matte intrigued the researcher to see the effect between Work Discipline on Employee Performance at PT. Semen Bosowa Banyuwangi. This research is an observational analytic study with a quantitative approach and a crosssectional study design. The research sample was 73 people, taken randomly using disproportionate stratified random sampling. Data collection includes Work Discipline and Worker Performance. The data analysis used in this study is a simple linear regression test. The results showed that there was an influence between Work Discipline on employee performance ( $\Sigma=0.001$ ), The conclusion of this study is even though PT. Semen Bosowa Workers have high Work Discipline the performance of workers who are in PT. Semen Bosowa Banyuwangi is good but not optimal.
\end{abstract}

Keywords: Work Discipline, Work Performance.

\title{
PENDAHULUAN
}

Sesuai dengan bidang Kesehatan Masyarakat maka didalamnya juga akan membahas Kesehatan Masyarakat Industri, dengan kata lain kita membicarakan Kesehatan dan Keselamatan Kerja (K3). Psikologi Industri merupakan salah satu cabang yang ada dalam K3 dimana didalamnya mempelajari perilaku manusia di tempat kerja. Perilaku manusia sangat berpengaruh terhadap roda - roda organisasi dikarenakan Sumber daya manusia (SDM) merupakan asset untuk perusahaan, jika tidak ada pekerja maka perusahaan tidak akan dapat menghasilkan laba atau meningkatkan nilai nya sendiri (1).

Pekerja akan dituntut untuk memiliki nilai moral di tempat kerja. Salah satu sikap moral yang harus dimiliki oleh pekerja adalah Disiplin kerja. Disiplin kerja mempunyai pengaruh yang paling dominan dalam mempengaruhi kinerja pekerja (2). Pekerja yang tidak mempunyai kesadaran mengenai disiplin kerja akan mengalami kesalahan yang sama dan menurunkan kinerja mereka (3). Seperti hasil dari penelitian (Nimpono, 2015), Ketidakdisiplinan pekerja pada instansi seperti tidak masuk kerja tanpa alasan, membuat proses dan kualitas produksi terhambat dan menurun (4). Sehingga dapat disimpulkan bahwasanya ketika Disiplin Kerja disebuah perusahaan buruk makan Kinerja pekerja juga akan menurun.

Pengambilan data awal dilakukan terhadap 11 responden di PT. Semen Bosowa 
Banyuwangi untuk melihat apakah terdapat masalah mengenai disiplin kerja dan Kinerja pekerja di PT. Semen Bosowa Banyuwangi. Hasil dari Pengambilan data awal terlihat bahwasanya terdapat $72 \%$ Pekerja memiliki Skor Disiplin Kerja yang masih dibawah total rata - rata Skor $(4,02)$, didapatkan juga bahwasanya masih terdapat $27 \%$ pekerja yang masih memiliki Skor Kinerja dibawah total rata - rata skor $(3,88)$. Melihat hasil Pengambilan data awal yang dilakukan peneliti tertarik untuk melihat Pengaruh disiplin kerja terhadap kinerja yang ada di PT. Semen Bosowa Banyuwangi.

\section{METODE}

Jenis penelitian ini merupakan penelitian Analitik, dengan menggunakan rancang bangun penelitian cross-sectional. Penelitian bersifat observasional karena tidak dilakukan intervensi kepada subjek penelitian, peneliti hanya melakukan penggalian informasi dan pengumpulan data. Variabel dependen dalam penelitian ini yaitu Kinerja Pekerja. Sedangkan variabel independen yang digunakan di penelitian ini adalah Disiplin Kerja. Disiplin kerja dan Kinerja Pekerja yang dimaksud ialah disiplin kerja dan kinerja pekerja di PT. Semen Bosowa Banyuwangi. Pengambilan data menggunakan data primer dimana peneliti menggunakan dua kuesioner Disiplin Kerja dan Kinerja Pekerja sebagai instrument penelitian, dan data sekunder yang berasal dari laporan yang sudah ada di PT. Semen Bosowa Banyuwangi. Populasi dari penelitian ini adalah seluruh pekerja yang ada di PT. Semen Bosowa Banyuwangi yaitu sebanyak 92 orang.

Teknik pengambilan sampel pada penelitian ini menggunakan teknik probability sampling, yaitu disproportionate Stratified Random Sampling dimana setiap subjek dalam populasi memiliki peluang yang sama untuk terpilih maupun tidak terpilih sebagai responden, dan perhitungan sampel menggunakan rumus binomunal proportion. Metode tersebut dipilih karena merupakan cara yang diggunakan peneliti untuk menjamin keterwakilan data yang dibutuhkan ketika jumlah populasi penelitian diketahui. Hasil dari penghitungan sample adalah sebesar 73 Responden.

Pengambilan data berasal dari Data primer yang didapatkan dari penyebaran kuesioner terhadap responden. Data yang diperoleh selanjutnya akan dilakukan analisis secara statistik mengenai Pengaruh Disiplin kerja terhadap Kinerja pekerja PT. Semen Bosowa Banyuwangi. Uji yang akan diggunakan adalah uji regresi linear sederhana. 


\section{HASIL}

\section{Gambaran Disiplin Kerja di PT.Semen Bosowa Banyuwangi}

Tabel 1.

Hasil Pengukuran Variabel Disiplin Kerja di PT. Semen Bosowa Banyuwangi

\begin{tabular}{lll}
\hline Kategori & $\mathbf{n}$ & $\mathbf{\%}$ \\
\hline Sedang & 19 & 26 \\
Tinggi & 54 & 74 \\
Total & $\mathbf{7 3}$ & $\mathbf{1 0 0}$ \\
\hline
\end{tabular}

Sumber : Data Primer, 2020

Berdasarkan tabel 1 dapat diketahui bahwa PT Semen Bosowa Banyuwangi memiliki Disiplin kerja yang tinggi yaitu sebanyak 54 responden yang mempunyai Disiplin kerja yang tinggi.

\section{Gambaran Kinerja Pekerja di PT. Semen Bosowa Banyuwangi}

Tabel 2

Hasil Pengukuran Variabel Kinerja Pekerja di PT. Semen Bosowa Banyuwangi

\begin{tabular}{|c|c|c|}
\hline Kategori & $\mathbf{n}$ & $\%$ \\
\hline Sedang & 60 & 82,2 \\
\hline Tinggi & 13 & 17,8 \\
\hline Total & 73 & 100 \\
\hline
\end{tabular}

Sumber : Data Primer, 2020

Pada Tabel 2 dapat teridentifikasi bahwa PT. Semen Bosowa Banyuwangi memiliki Kinerja Pekerja yang masuk kedalam kategori Sedang dengan 60 Responden.

\section{Pengaruh Disiplin Kerja terhadap Kinerja Pekerja PT. Semen Bosowa Banyuwangi}

Pengaruh Disiplin Kerja terhadap kinerja pekerja PT. Semen Bosowa Banyuwangi pada tabel 2 menunjukan bahwa Sebagian besar Disiplin Kerja yang ada di PT. Semen Bosowa Banyuwangi ada pada kategori Tinggi. Uji statistik yang digunakan untuk menganalisis pengaruh Disiplin Kerja terhadap kinerja pekerja PT. Semen Bosowa Banyuwangi adalah regresi linier sederhana. Adapun hasil uji statistik ditampilkan dalam tabel berikut: 
Tabel 3

Hasil Tabel Model Summary antara Disiplin Kerja Terhadap Kinerja Pekerja

\begin{tabular}{ccccc}
\hline Model & $\mathbf{R}$ & $\mathbf{R}^{2}$ & Adjusted $\boldsymbol{R}^{2}$ & Std. Error of the Estimate \\
\hline 1 & .395 & .156 & .144 & 3.966 \\
\hline
\end{tabular}

Sumber : Data Primer, 2020

Tabel 3 didapatkan Nilai $\mathrm{R}$ sebesar 0.395 yang dapat diartikan variable Disiplin Kerja berhubungan dengan Kinerja Pekerja di PT. Semen Bosowa Banyuwangi dengan keeratan hubungan sebesar 0.395. R Square pada tabel 3 dapat diartikan bahwasanya Disiplin Kerja berpengaruh terhadap Kinerja Pekerja sebesar 15,6\%.

Tabel 4

Hasil Uji Statistik Pengaruh Disiplin Kerja Terhadap Kinerja Pekerja di PT. Semen Bosowa Banyuwangi

\begin{tabular}{cccccc}
\hline Model & \multicolumn{2}{c}{$\begin{array}{c}\text { Unstandardized } \\
\text { Coefficients }\end{array}$} & $\begin{array}{c}\text { S. } \\
\text { Coefficients }\end{array}$ & t & \multirow{2}{*}{ Sig. } \\
\cline { 2 - 4 } & $\mathbf{B}$ & $\begin{array}{c}\text { Std. } \\
\text { Error }\end{array}$ & Beta & & \\
& & & & \\
\hline (Constant) & 15.320 & 5.153 & .395 & 2.973 & 0.004 \\
Disiplin Kerja & .463 & .128 & & 3.618 & 0.001 \\
\hline
\end{tabular}

Sumber : Data Primer, 2020

Berdasarkan tabel 4 dapat diketahui bahwa nilai signifikan ( $p$ value) untuk Disiplin Kerja adalah 0.001 dan lebih kecil dari $\alpha=5 \%(0,05)$ sehingga H0 ditolak, dimana disiplin kerja berpengaruh terhadap kinerja pekerja PT. Semen Bosowa Banyuwangi. Selain itu diperoleh juga koefisien Regresi disiplin kerja yang bernilai positif sebesar 0.463, yang dapat diartikan arah Pengaruh Disiplin Kerja terhadap Kinerja pekerja adalah Positif.

\section{PEMBAHASAN}

Disiplin Kerja adalah kesadaran dan kesediaan seseorang untuk menaati semua peraturan dan norma - norma yang ada di perusahaan dimana dia bekerja (5). Ketaatan pada peraturan kerja merupakan salah satu indikator dari Disiplin Kerja. Pekerja di PT. Semen Bosowa Banyuwangi menaati peraturan kerja yang ada di perusahaan, seperti penggunaan Alat Pelindung Diri Pada wilayah tertentu, dimana saat peneliti datang untuk melakukan penelitian, peneliti juga diwajibkan untuk menggunakan Alat Pelindung diri di wilayah 
tertentu. Sehingga dari sini dapat terlihat bahwasanya PT. Semen Bosowa Banyuwangi menetapkan kedisiplinan yang baik.

PT. Semen Bosowa Banyuwangi juga memliki kewaspadaan yang tinggi, hal ini dapat dilihat dari ditunjuknya beberapa pekerja sebagai penanggung jawab di beberapa Departemen untuk melakukan pengawasan di masing - masing wilayah yang berbeda sehingga jika terjadi sesuatu dapat segera dilaporkan dan diatasi. Hal tersebut dibuktikan dari hasil penelitian untuk mengidentifikasi Disiplin Kerja yang ada di PT. Semen Bosowa Banyuwangi dimana terdapat 54 Responden (74\%) yang mempunyai Disiplin Kerja yang Tinggi. Sesuai dengan Teori yang dikatakan oleh (Rivai, 2005), bahwasanya pekerja yang mempunyai tingkat kewaspadaan tinggi akan selalu perhitungan, berhati-hati serta akan selalu menggunak sumber daya secara efektif dan effisien, sehingga disiplin kerja dari pekerja tersebut pun akan $\operatorname{baik}(6)$.

Kinerja Pekerja memiliki pengaruh terhadap produktivitas, sebab kinerja dapat diartikan menjadi usaha karyawan untuk mencapai tujuan melalui produktivitas kerja yang ditampakkan secara kuantitas maupun kualitas (7). Keberhasilan seseorang dalam melakukan pekerjaan nya sesuai dengan tanggung jawab dan wewenang masing - masing atau bagaimana seseorang diharapkan dapat berperilaku dan berfungsi sesuai dengan pekerjaan dan tanggung jawab yang sudah diberikan kepadanya serta kuantitas, kualitas dan waktu yang digunakan dalam menjalankan pekerjaan tersebut (8).

Hasil pengukuran pada Kinerja Pekerja di PT Semen Bosowa menghasilkan tidak adanya responden yang mempunyai kinerja yang rendah, namun responden dominan memiliki kinerja yang masuk kedalam kategori sedang yaitu sebanyak 60 Responden $(82,2 \%)$. Hasil tersebut menunjukan belum maksimalnya Kinerja Pekerja yang berada di PT. Semen Bosowa Banyuwangi. Kinerja yang ditunjukan tersebut sudah baik akan tetapi masih terdapat ruang untuk mengoptimalkan kinerja tersebut. Tidak maksimalnya kinerja pekerja di PT. Semen Bosowa banyuwangi dapat disebabkan oleh beberapa faktor, seperti tingkat pengetahuan pekerja, tingkat inisiatif pekerja, tingkat kemampuan dan kecepatan dalam menerima instruksi kerja serta motivasi dan sikap pekerja dalam melaksanakan kerjanya(8).

Hasil uji statistik dengan regresi linier sederhana, antara Disiplin kerja terhadap Kinerja pekerja diperoleh hasil bahwa terdapat pengaruh antara Disiplin Kerja terhadap Kinerja Pekerja di PT. Semen Bosowa Banyuwangi. Hasil yang diperoleh tersebut dapat mendukung atau memperkuat teori yang ada dimana disiplin kerja merupakan salah satu 
faktor yang mempengaruhi kinerja pekerja (8). Sebagaimana hasil penelitian yang dilakukan oleh (Shanggamu dan Mandey, 2014), bahwa variabel Disiplin Kerja signifikan dan berpengaruh terhadap kinerja karyawan (9).

Disiplin dibutuhkan untuk tujuan organisasi yang lebih jauh guna menjaga efisiensi dengan mencegah dan mengkoreksi Tindakan-tindakan individu dalam itikad baiknua terhadap kelompok (8). Hasil uji statistik juga menyatakan bahwasanya pengaruh Disiplin Kerja terhadap Kinerja Pekerja di PT. Semen Bosowa Banyuwangi mempunyai pengaruh yang positif, dimana jika Disiplin Kerja Meningkat maka akan berpengaruh terhadap Peningkatan Kinerja Pekerja di PT. Semen Bosowa Banyuwangi.

Penelitian serupa oleh (Syafrina, 2017), bahwa Disiplin Kerja berpengaruh positif dan signifikan terhadap kinerja karyawan dimana semakin meningkat disiplin kerja karyawan, maka kinerja karyawan juga akan meningkat (10). Menurut Penelitian (Mellany dan Ibrahim, 2015), dimana Disiplin Kerja yang diterapkan diperusahaan membuat pekerja bersungguh sungguh dalam melaksanakan pekerjan yang diberikan, hal tersebut berkaitan erat dengan kinerja pekerja (11).

Perusahaan yang memiliki disiplin kerja yang baik maka Kinerja Pekerja untuk mencapai tujuan organisasi juga akan meningkat. Hal tersebut sejalan dengan keadaan di PT. Semen Bosowa dimana pekerja nya setuju untuk berada ditempat kantor sampai dengan waktu yang ditentukan untuk melaksanakan pekerjaan yang sudah diberikan ke masing masing pekerja. Hal ini menyebabkan kesungguhan pekerja dalam melakukan pekerjaan sehingga kinerja pekerja nya pun meningkat. Penelitian tersebut juga sejalan dengan penelitian (Astutik, 2016), dimana dinyatakan Disiplin Kerja berpengaruh positif terhadap kinerja pekerja, karena kehadiran pekerja, dimana pekerja setuju untuk hadir dikantor sesuai dengan jam yang ditentukan untuk melakukan pekerjaan nya (12).

Menurut Penelitian (Wairooy, 2017), menyatakan dimana disiplin kerja berpengaruh positif dan signifikan terhadap kinerja pekerja yang berarti ketika pekerja pada sebuah perusahaan memiliki disiplin kerja yang tinggi maka akan berpengaruh dan meningkatkan kinerja pekerja tersebut (13). Penelitian ini sejalan dengan Hasil Penelitian di PT. Semen Bosowa Banyuwangi dimana dapat dilihat karena Disiplin Kerja yang tinggi, maka kinerja pekerja yang dihasilkan juga baik. Penelitian ini juga sejalan dengan penelitian (Sunarsi, 2017), dimana disiplin kerja terbukti berpengaruh positif dan siginifikan terhadap kinerja pekerja (14). Penelitian tersebut juga sejalan dengan penelitian (Husein, 2018), dimana 
didapatkan terdapat pengaruh yang positif dan signifikan antara Disiplin Kerja terhadap Kinerja Pekerja, yang dapat diartikan bahwasanya jika Disiplin kerja mengalamin peningkatan maka Kinerja pekerja-pun juga akan meningkat (15).

\section{KESIMPULAN DAN SARAN}

Berdasarkan Penelitian ini dapat disimpulkan bahwasanya Disiplin Kerja yang dimiliki oleh Pekerja di PT. Semen Bosowa Banyuwangi didominasi dengan Disiplin Kerja yang tinggi dan sedang dan tidak ada responden yang memiliki disiplin kerja yang rendah, namun Kinerja Pekerja di PT. Semen Bosowa Banyuwangi tidak adanya responden yang mempunyai kinerja yang rendah, namun responden dominan memiliki kinerja yang masuk kedalam kategori sedang Sehingga dapat disimpulkan bahwasanya Kinerja Pekerja yang berada di PT. Semen Bosowa Banyuwangi belum optimal. Terdapat pengaruh positif dan signifikan antara Disiplin Kerja dengan Kinerja Pekerja, dimana Pekerja di PT Semen Bosowa mempunyai Disiplin Kerja yang tinggi maka kinerja nya juga baik.

\section{DAFTAR PUSTAKA}

1. Taufiqurokhman. Mengenal Manajemen Sumber Daya Manusia. Universitas Prof. Dr. Moestopo Beragama; 2009.

2. Ahmad Nur Rofi, SE MS. Pengaruh Disiplin Kerja Dan Pengalaman Kerja Terhadap Prestasi Kerja Karyawan Pada Departemen Produksi Pt. Leo Agung Raya Semarang. Ilmu Manaj daan Akunt Terap. 2012;

3. Ayu Maya Prabasari I, Salit Ketut Netra I. Pengaruh Motivasi, Disiplin Kerja Dan Komunikasi Terhadap Kinerja Karyawan Pada Pt. Pln (Persero) Distribusi Bali. E-Jurnal Manaj Univ Udayana. 2013;

4. Nimpuno GA. Pengaruh Displin Kerja Dan Gaya Kepemimpinan Terhadap Kinerja Karyawan UD. Pustaka Pelajar Yogyakarta. Skripsi. 2015.

5. Hasibuan MSP. Manajemen Sumber Daya Manusia. Ed Revisi Jakarta Bumi Aksara. 2011;

6. Rivai V, Basri. Performance Appraisal: Sistem yang Tepat untuk Menilai Kinerja Karyawan dan Meningkatkan daya saing Perusahaan. PT Raja Grafindo Persada; 2005.

7. Wijono S. Psikologi Industri \& Organisasi : dalam suatu bidang gerak Psikologi Sumber Daya Manusia. Prenadamedia Group,2010;

8. Sutrisno E. Manajemen Sumber Daya Manusia, Jakarta. PT. Prenada Media Group; 2010.

9. Partricia MS, Silvya LMa. Pengaruh Pelatihan Kerja, Motivasi, Dan Disiplin Kerja Terhadap Kinerja Karyawan Pada PT. Bank Perkreditan Rakyat Dana Raya. J Ris Ekon Manajemen, Bisnis dan Akunt. 2014;

10. Syafrina N. Pengaruh Disiplin Kerja Terhadap Kinerja Karyawan Pada PT. Suka Fajar Pekan Baru. Eko dan Bisnis. 2017; 
11. Mellany P, Ibrahim M. Pengaruh Disiplin Kerja terhadap Kinerja Karyawan (Kasus Bagian Operasional PT Indah Logistik cargo Cabang Pekanbaru). J Online Mhs Fak Ilmu Sos dan Ilmu Polit Univ Riau. 2015;2(2).

12. Mardi Astutik. Pengaruh Disiplin Kerja Dan Budaya Organisasi Terhadap Kinerja Pegawai Sekretariat Dewan Perwakilan Rakyat Daerah Kabupaten Jombang Mardi Astutik Abstrak Pendahuluan. J Bisnis, Manaj Perbank. 2016;

13. Wairooy A. Pengaruh Disiplin Kerja dan Kompensasi Terhadap Kinerja Karyawan pada PT. Pertamina (Persero), Tbk. Pemasaran Region VII Makassar. J Ad'ministrare. 2017;

14. Sunarsi D. Pengaruh Gaya Kepemimpinan dan Disiplin Kerja Terhadap Kinerja Karyawan Pada CV. Usaha Mandiri Jakarta. JENIUS (Jurnal Ilm Manaj Sumber Daya Manusia). 2018;

15. Husain BA. Pengaruh Disiplin Kerja Terhadap Kinerja Karyawan (Pada Pt. Bank Danamon Tbk Cabang Bintaro). JENIUS (Jurnal Ilm Manaj Sumber Daya Manusia). 2017; 